\title{
A prevenção de incêndios florestais no estado de Minas Gerais
}

\author{
Gumercindo SouZa Lima
}

Palavras-chave: prevenção, incêndios florestais, proteção florestal

\section{INTRODUÇÃO}

O incêndio florestal tem destruído, anualmente, grandes extensões territoriais no Brasil de cobertura florestal nativa. Em Minas Gerais não é diferente, em especial em algumas regiões onde as condições climáticas favorecem a propagação intensa do fogo, como é o caso do Estado de Minas Gerais. O Clima seco no final do inverno, associado aos costumes e modo de produção com uso do fogo como prática agrícola possibilitam a ocorrência de incêndios florestais em várias regiões do estado ao mesmo tempo.

Em 1999, houve no Estado uma área queimada de cerca de 12.000 ha, somente nas Unidades de Conservação estaduais, pelo menos 40.000 ha nas Unidades de Conservação federais, e uma liberação de área para queima controlada de 90.000 ha. Uma área significativa, ainda, é atingida todos os anos pelas queimas não autorizadas, incêndios em áreas particulares, incêndios em margens de rodovias, queimas de lotes urbanos e outros.

Em 2000, graças a uma forte ação do IEF na prevenção e controle do uso do fogo, além do favorecimento climático, pela melhor distribuição pluviométrica, essa área queimada representa cerca de 70\% do ano anterior.

A grande área queimada e o alto número de focos de calor ocorridos nos últimos anos no Brasil têm exposto a fragilidade do país no controle de seus incêndios florestais. A principal deficiência do país é a falta de política nacional e regional de prevenção e combate a incêndios. Os trabalhos de prevenção têm sido precários e geralmente construídos anualmente já no início da temporada de fogo. 
O Estado de Minas Gerais possui uma área de 58.675.300,0 ha. Dividido em 853 Municípios, com população aproximada de 16.673.097 habitantes. O Estado possui atualmente 36 unidades de conservação (19 parques estaduais, 10 reservas biológicas, 7 estações ecológicas), com área total protegida, em unidades de uso indireto, administrado pelo Estado de 355.000,00 ha (equivalente a 0,61\% do território do estado).

Além das áreas administradas pelo estado, Minas Gerais possui ainda cerca de 3.700 ha de unidades de uso indireto administrado pelos municípios e 420.000 ha administrados pela União, totalizando no Estado, portanto, $778.770,00$ ha, que representam 1,35\% do território mineiro.

As principais Unidades de Conservação de uso indireto administradas pelo Estado, que tem sofrido maior ação do fogo são: P.E. Serra do Rola Moça, P.E. Rio Doce, P.E. Serra do Brigadeiro, P. E do Rio Preto, P. E do Ibitipoca, P.E. do Itacolomi. As Unidades de Conservação administradas pela União, principalmente pelas grandes extensões e maiores dificuldades de se monitorar, têm apresentado mais ocorrências de fogo e maiores áreas queimadas, como, por exemplo: P.N. Serra da Canastra, P.N. da Serra do Cipó, P.N. da Serra do Caparaó, P.N. Grande Sertão Veredas.

Grande parte dos incêndios ocorrida no Estado de Minas Geral tem seu início nas margens das rodovias. A malha viária mineira é a maior do país $(272.000 \mathrm{~km})$, seguido por São Paulo com $198.000 \mathrm{~km}$. Por estas razões as margens de rodovias merecem atenção especial, assim como as Unidades de Conservação, quanto ao planejamento de prevenção e combate a incêndios florestais em Minas Gerais.

Os principais biomas presentes no Estado de Minas Gerais são o Cerrado, cujos domínios ocupam aproximadamente 52\%, e a Mata Atlântica, que ocupa cerca de $26 \%$ da cobertura vegetal. As condições climáticas são bastante variáveis entre as regiões sul/sudeste e a norte, que possui estação seca muito definida.

O uso do fogo como prática agrícola também é bastante diferenciado na região norte o principal uso é para queima de restos de cultura ou limpeza de terreno para plantio, enquanto nas regiões sul, oeste e leste há um uso predominante para renovação das pastagens. Em algumas regiões do Estado, como no Vale do Rio Doce o uso constante do fogo para renovação de pastagens tem levado a um estado de degradação acentuada, com processos erosivos avançados. 


\section{A ESTRUTURA DO ESTADO PARA PREVENÇÃO E COMBATE AOS INCÊNDIOS FLORESTAIS}

A partir de ampla discussão com o meio técnico-científico e sociedade organizada se originou a LEI 10.312, de 12 de novembro de 1990 ("Lei de Incêndios Florestais") e a elaboração de um programa para viabilizar o início da implantação do então denominado Sistema Integrado de Prevenção e Combate a Incêndios Florestais. O Instituto Estadual de Florestas - IEF/MG, conforme o prescrito na Lei Estadual 10.312, de 12 de novembro de 1990, que dispõe sobre a prevenção e o combate aos incêndios florestais e ratificados pela Lei Florestal Estadual 10.561, de 27 de dezembro de 1991, que dispõe sobre a política florestal do Estado, tornou-se o órgão responsável, no Estado de Minas Gerais, pela coordenação dos trabalhos de prevenção e combate aos incêndios florestais.

No ano 2000 iniciou-se a implantação definitiva do Plano Estadual de Prevenção e Combate aos Incêndios Florestais. O Estado de Minas Gerais com recursos oriundos do Banco de Crédito Alemão (KFW), no valor de 14 milhões de marcos, aumenta a proteção das Unidades de Conservação do Estado, situadas no bioma Mata Atlântica (Programa de Proteção da Mata Atlântica - Pró-Mata). Além disso, houve um aumento significativo dos recursos do tesouro Estadual, investidos na proteção contra incêndios florestais em Unidades de Conservação do Estado.

Para desenvolver estudos técnicos e elaborar o Plano de Prevenção contra Incêndios Florestais em Minas Gerais, o Governo do Estado, através do IEF, criou o Centro de Estudos em Incêndios Florestais (CEIF), em convênio com a Universidade Federal de Viçosa (UFV) e a Sociedade de Investigações Florestais (SIF). O CEIF está sediado no Campus da Universidade Federal de Viçosa, e conta com o apoio do corpo técnico do Departamento de Engenharia Florestal da UFV.

O Estado conta, atualmente, com 36 brigadas de combate incêndios, localizadas no entorno das Unidades de Conservação. Essas brigadas são constituídas em média por 25 pessoas e são, em sua maioria, formadas por servidores públicos, funcionários de empresas privadas, agricultores e ambientalistas, que são treinados e reciclados anualmente pelo Corpo de Bombeiros de Minas Gerais e pelo IEF. Junto a cada brigada são mantidos equipamentos e ferramentas de combate a incêndios florestais, como: Pinga-fogo, bomba-costal, 
abafadores, chicotes, pás, enxadas, motosserras, luvas, cantis, máscaras, mochilas, etc...

O IEF conta, ainda, com um helicóptero para combate a incêndios, tipo esquilo, equipado com "bambi-bucket" (bolsas para transporte de água) e reservatório de armazenamento em solo. Além deste helicóptero o IEF possui convênio com a Polícia Militar (CORPAER - Corporação de Patrulhamento Militar Aéreo), no sentido de utilizar outras aeronaves, caso se faça necessário, durante o combate.

O Estado de Minas Gerais, a exemplo dos outros estados da região centro-sul do país, teve em 1999 uma alta frequiência de incêndios, nos meses secos, com destaque para os meses de agosto e setembro. Esses dados podem ser confirmados através do trabalho iniciado pelo Instituto Estadual de Florestas, a partir de junho de 1999, que é o monitoramento dos focos de incêndio que ocorrem no estado, através dos satélites NOAA-12 e NOAA-14, permitindo assim uma melhor visualização da distribuição dos incêndios em todo o Estado. $\mathrm{O}$ monitoramento dos focos de calor por região tem permitido um melhor planejamento das ações e estabelecimento das estratégias regionais, além de se conseguir uma maior sensibilização pública para a problemática do fogo em Minas Gerais.

\section{ESTRATÉGIA DE PREVENÇÃO DE INCÊNDIOS FLORESTAIS EM MINAS GERAIS}

Entende-se pelas dimensões do Estado de Minas Gerais e pela grande diversidade cultural, climática e de ambientes fitogeográficos, que uma estratégia adequada de prevenção e combate aos incêndios florestais só terá sucesso se consideradas as particularidades regionais. A identificação do grupo principal de causas e a relação de uso da terra, por região, é a premissa básica mais importante para o planejamento de controle do fogo. Com o objetivo de reduzir a ocorrência de incêndios florestais, e aumentar o controle do uso do fogo, o Estado de Minas Gerais apresentou neste ano as seguintes estratégias de prevenção de incêndios:

\section{a. CAMPANHA DE CONTROLE DE INCÊNDIOS (CACIF- 2000)}

O Estado de Minas Gerais lançou neste ano, sob a coordenação do Instituto Estadual de Florestas a Campanha de Controle de Incêndios 
Florestais (CACIF-2000), integrando as atividades de diversos órgãos e instituições que atuam no estado para a prevenção dos incêndios. Todos os anos diversos órgãos lançam suas próprias campanhas de controle de incêndios, o que acarreta em sobreposição de trabalhos que podem gerar conflitos para a opinião pública sobre a problemática. Com isso, algumas regiões ficam exageradamente trabalhadas sobre a prevenção de incêndios, em detrimento de outras que por não estarem dentro do raio de ação destas empresas e instituições ficam totalmente descobertas. Dentre as instituições e empresas que integraram a CACIF-2000, podemos citar: Instituto Estadual de Florestas, Corpo de Bombeiros Militar, CEMIG, EMATER, Minerações Brasileiras Reunidas, Companhia Estadual de Saneamento, Sociedade de Investigações Florestais, Centro Mineiro para a Conservação da Natureza, Universidade Federal de Viçosa, Celulose Nipo-Brasileira, Companhia de Aços Gerdau, Departamento Estadual de Estradas de Rodagem DER/MG, DNER, Mannesmann Florestal, Polícia Rodoviária Federal, entre outras.

Com o slogan "Chega de chamas! Fogo só Controlado", a CACIF-2000 apresenta a visão conceitual de que o fogo pode ser empregado desde que devidamente planejado e recomendado por técnico ou instituição competente para tal.

Diversas atividades foram desenvolvidas, tais como: Fiscalização educativa nas diversas rodovias do estado, veiculação educativa e participação em programas de entrevistas e debates em rádios e televisões, dias de campo, visitas aos produtores rurais, distribuição à sociedade de materiais educativos alusivos ao problema do fogo. Todas essas programações procuraram ser desenvolvidas em níveis regionais, mas com a visão global do estado.

\section{b. MAPAS DE RISCO DE INCÊNDIO}

O Estado de Minas Gerais foi dividido em 13 regiões, de acordo com a atuação administrativa do Instituto Estadual de Florestas, e para cada região administrativa e para cada área de atuação dos escritórios florestais, foram confeccionados mapas de risco de incêndios florestais, classificando os municípios em áreas de pequeno, médio e alto risco de incêndio. Os mapas de risco são, além de excelente ferramenta de planejamento ambiental, uma forma eficaz de sensibilizar a opinião pública para o problema do fogo. Cada escritório administrativo regional e cada escritório florestal recebeu o seu mapa de 
risco, podendo, assim, melhor planejar suas ações na época crítica de fogo no estado.

\section{c. CALENDÁRIO DE QUEIMA CONTROLADA}

Queima controlada pode ser definida como o emprego do fogo como qualquer outra ferramenta, para atender os mais variados objetivos do manejo da terra. Para tanto, deve-se estar atento para que os objetivos positivos sejam maximizados e os efeitos negativos minimizados. Uma queima controlada não implica apenas no confinamento do fogo numa área limitada; ela exige um planejamento em que, entre outros parâmetros, deve ser considerada a temperatura e a velocidade de queima, o consumo de material combustível, a altura de crestamento, a altura de carbonização e os aspectos legais, ligados principalmente à permissão para a execução da queima. Esses parâmetros podem ser controlados de diversas formas como através da técnica de queima, monitoramento das condições de material combustível, regime de queima e condições meteorológicas.

No Brasil, todos os anos, o número de incêndios florestais é bastante alto nos meses mais secos, e no Estado de Minas Gerais correspondem aos meses de julho, agosto, setembro e meados de outubro. Esta época coincide também com a queima para renovação de pastagens nas propriedades rurais e a queima para limpeza do terreno para plantio, que se dará logo após as primeiras chuvas.

Neste período, foram feitas nos escritórios do Instituto Estadual de Florestas - IEF cerca de 4000 liberações de pedidos de queima controlada. Em alguns municípios, como Andrelândia e São Roque de Minas, chega-se a registrar cerca de 500 pedidos de queima para renovação de pastagens por ano. Com essa grande pressão torna-se inviável a vistoria prévia nas propriedades pelo técnico do IEF, que muitas vezes é obrigado a agir sob pressão. O lançamento do calendário de queima visa acobertar a atuação do técnico do escritório florestal com um documento que tecnicamente recomenda o uso do fogo, definindo as épocas do ano em que é permitida a queima no município.

O calendário de queima define as épocas do ano em que será permitida a emissão de autorização pelo escritório florestal em cada município mineiro. Esse planejamento foi baseado no histórico de cada município em termos de demanda diária e mensal para solicitação de queima e no número de focos de calor registrados diariamente em cada município mineiro nos anos anteriores. O Calendário de Queima tem, 
ainda, um importante apelo educativo, pois o mesmo está sendo distribuído a todos os proprietários rurais e junto deste segue orientações de como fazer uma queima controlada, além de outras informações educativas para $o$ agricultor.

O Centro de Estudos em Incêndios Florestais (CEIF), irá avaliar anualmente o emprego do calendário de queima e providenciar os ajustes necessários para garantir a sua eficácia no controle e no planejamento de uso do fogo. 